\title{
Conflitos socioambientais brasileiros à luz de princípios norteadores do direito ambiental
}

\section{Socioenvironmental conflicts from the point of view of guiding principles of environmental law}

\author{
1 Thairone de Sousa Paiva thaironepaiva@gmail.com \\ 1 Patrícia Borba Vilar Guimarães
}

1 Universidade Federal do Rio Grande do Norte.

\section{Resumo}

A pesquisa tem por objetivo analisar casos específicos em território brasileiro que se enquadrem no conceito de conflito socioambiental. Os recursos naturais, os espaços geográficos e a sustentabilidade social contemporânea contrastam com ideias neoliberais e de desenvolvimento econômico que, desde o fim do século XX, defendem a autonomia do indivíduo sobre sua propriedade independentemente de fatores ambientais externos coexistentes no mesmo território. Essa divergência na harmonização entre o bem privado juridicamente tutelado e o meio ambiente difuso foi capaz de gerar conflitos socioambientais diversos espalhados em território nacional, dentre os quais são abordados o rompimento de uma barragem em Mariana/MG no ano de 2015, o conflito judicial sobre a posse de um território em um município do RN e a imigração de venezuelanos ao estado de Roraima em 2018. O método utilizado é o indutivo, baseando-se em casos concretos, na legislação, doutrina e jurisprudência pertinentes ao estudo. Em conclusão, apesar de ser defendido o caráter indissolúvel entre os princípios e os casos concretos, o direito prático que incide sobre os conflitos socioambientais é, diversas vezes, atrelado à manutenção do status quo do Estado enquanto monopólio legítimo da força coercitiva, sem utilizar como base os princípios articulados nas conferências internacionais, os interesses das partes e a justiça do caso concreto.

\section{Palavras-chave}

Direito ambiental. Direito urbanístico. Conflitos socioambientais.

\begin{abstract}
The research aims to analyze specific cases in Brazilian territory that fit into the concept of social and environmental conflict. Natural resources, geographical spaces and contemporary social sustainability contrasts with the ideas of liberal and economic development that, since the end of the 20th century, advocate the individual autonomy on his or hers property regardless of external environmental factors coexisting in the same territory. This divergence in harmonization between private good legally tutored and the diffuse environment was able to generate several socioenvironmental conflicts scattered in the national territory, from which and treated here the breaking of a dam in Mariana, Minas Gerais, in the year 2015, the legal conflict over ownership of a territory in a town of Rio Grande do Norte and the Venezuelan immigration to the State of Roraima in 2018. The method used is the inductive, based on specific cases, in legislation, doctrine and jurisprudence relevant to the study. In conclusion, despite being defended the indissoluble character between principles and concrete cases, the practical law that focuses on socioenvironmental conflicts is, several times, tied to the maintenance the State's status quo as legitimate monopoly of coercive force, without using as a basis the principles articulated in international conferences, the interests of the parties and the Justice of the case.
\end{abstract}

\section{Keywords}

Environmental law. Urban law. Socio-environmental conflicts.

\section{Como você deve citar?}

PAIVA, Thairone de Sousa; GUIMARÃES, Patrícia Borba Vilar. Conflitos socioambientais brasileiros à luz de princípios norteadores do direito ambiental. Cadernos UniFOA, Volta Redonda, n. 37, p. 69-80, ago. 2018. 


\section{INTRODUÇÃO}

A disponibilidade de recursos naturais é, no século XXI, uma das pautas mais abordadas em conferências nacionais e internacionais, principalmente quando se tem como objetivo a discussão de problemáticas relevantes para as sociedades atuais. A divisão geopolítica dos territórios, o outsourcing de países economicamente desenvolvidos sobre países subdesenvolvidos e as parcerias público-privadas são características de gestão atual que permitem que a busca pelo lucro sobreponha as necessidades ambientais de preservação ou restauração do meio ambiente.

Apesar de ser uma pauta relevante e amplamente discutida, a disponibilidade de recursos naturais e suas várias formas de preservação e restauração só obtiveram a atenção necessária na metade do século XX, tendo em vista a negligência estatal e do poder privado em fiscalizar os possíveis impactos negativos causados pelos meios de produção desenvolvidos desde a Revolução Industrial até a Guerra Fria, quando foi possível observar com nitidez os desastres causados por movimentos de desenvolvimento industrial, por novos meios de captação de energia e pelo histórico mundial de duas grandes guerras que causaram desastres ecológicos e ambientais de magnitudes nunca previstas por seus responsáveis.

Assim, surgem novos meios de readaptar os desenvolvimentos econômico e tecnológico às limitações ambientais, que, presentes em dispositivos jurídico-políticos e sociais (por meio de ONGs e movimentos de proteção ambiental), tentam reparar os danos causados por desastres passados e assegurar que não ocorram mais degradações ambientais.

Ainda nesse sentido, há a presença de conflitos que permeiam as diversas esferas sociais e que demandam espaços territoriais por diversos argumentos: de origem histórica, por aparato ambiental ou até mesmo por meio de projetos políticos de reparação de desigualdade social. Esses conflitos, denominados socioambientais, carecem da efetividade do Poder Público na realização de mediação do litígio, a fim de encontrar o melhor meio de utilização dessas terras.

Apesar da dificuldade na resolução desses conflitos, a República Federativa do Brasil dispõe de diversos instrumentos no ordenamento jurídico brasileiro, que se propõem a auxiliar na resolução de conflitos de ordem ambiental. Por meio de princípios, normas e resoluções, o Poder Público deve estabelecer a melhor forma de beneficiar os litigantes e garantir que o espaço territorial demandado exerça sua função social, prevista na Constituição da República de 1988.

Com isso, a presente pesquisa surge com o objetivo de analisar casos específicos em território brasileiro que se enquadrem no conceito de conflito socioambiental abordado no decorrer do artigo junto aos princípios norteadores do Direito Ambiental nos ordenamentos jurídicos brasileiro e internacional. Além disso, a pesquisa tem como objetivos específicos i. conceituar o termo "conflitos socioambientais"; ii. realizar um apanhado acadêmico dos princípios de Direito Ambiental; iii. identificar casos concretos que configurem conflitos socioambientais; e iv. relacionar os princípios norteadores de Direito Ambiental com os casos concretos detalhados no decorrer da pesquisa.

Assim, o presente trabalho surge no contexto acadêmico como uma forma de apresentar relações diretas entre os princípios norteadores de Direito Ambiental e as diversas facetas que os casos concretos apresentam no ordenamento jurídico e no meio social comum. Essa justificativa parte da premissa de que é necessário exercitar os conceitos principiológicos sobre Direito Ambiental no atual contexto, haja vista as mudanças no cenário político capazes de afetar o Poder Judiciário como monopólio do controle socioambiental, os projetos de desenvolvimento sustentável que carecem de amparo jurídico 
e a ausência de pautas socioambientais constantes em veículos de comunicação, que estão cada vez mais optando por debater assuntos de forma mais rápida e com o mínimo de interesse investigativo.

\title{
2 CONFLITOS SOCIOAMBIENTAIS
}

No âmbito da análise jurídica de casos concretos, é imprescindível a caracterização de cada litígio contendo suas particularidades como fatores determinantes para a conceituação dos conflitos. In casu, os conflitos analisados estão situados em uma área da seara jurídica que abrange os mesmos recursos naturais em interesse das partes, as classes socioeconomicamente divididas e os conflitos territoriais.

Nesse sentido, cabe ao jurista entender que o caso concreto carece de ferramentas próprias para a resolução da lide, recorrendo a doutrinadores que utilizam de matéria ambiental como o foco de seus trabalhos. É a partir daí que há a concretização do litígio como conflito socioambiental, haja vista que a matéria adotada em grande parte ou em todo caso concreto é de origem ambiental e, além disso, jurisprudências que antecedem o caso já abordaram casos similares.

\subsection{Conceito}

Diversos doutrinadores e pesquisadores tentam buscar a melhor definição para o termo "conflitos socioambientais". Apesar da tentativa de homogeneização dessa definição, alguns pesquisadores já entendem que a grande dificuldade está na forma que o autor observa o litígio. Assim, o conflito socioambiental deve partir da ideia de quem o está observando, variando de acordo com os ideais dispostos pelo observador.

\section{Segundo Carvalho \& Scotto (1995),}

o conflito socioambiental se apresenta como um conflito social que expressa uma luta entre interesses opostos, que disputam o controle dos recursos naturais e o uso do meio ambiente comum. Ou seja, é um conflito social que tem no acesso aos recursos naturais o seu principal objeto de disputa.

Assim, Carvalho \& Scotto evidenciam a busca pelo recurso natural como o objeto-chave do conflito em questão no momento da definição do termo, não havendo a individualização dos litigantes em si, mas focando no objeto posto em litígio.

Já, para Acselrad (2004 apud Brito et al., 2011, p. 56),

\begin{abstract}
os conflitos socioambientais ocorrem quando são envolvidos grupos sociais com modos diferenciados de apropriação, uso e significado do território. São originados quando pelo menos um dos grupos sofre ameaças quanto à continuidade das formas sociais de apropriação do seu meio. Estas ameaças podem acontecer por impactos indesejáveis ocorridos com o solo, água, ar ou sistemas vivos, decorrentes do exercício e das práticas de outros grupos. Ou seja, o conflito socioambiental é visualizado quando os agentes sociais estabelecem uma associação lógica imediata entre a degradação do ambiente e a ação dos agentes sociais determinados sob dadas condições históricas".
\end{abstract}

Nesse sentido, Ascelrad se opõe ao modelo de análise limitada ao objeto de litígio e busca averiguar também as posições adotadas pelos responsáveis pelo conflito. Assim, há uma facilidade maior de identificar, por exemplo, a origem do conflito, as demandas assumidas pelos litigantes e até mesmo a proporção de consequências ambientais que podem surgir com a não resolução do litígio.

Já no contexto dos conflitos socioambientais em terras brasileiras, Alves e Santos (2017, p. 221) citam que "os casos de conflitos socioambientais no Brasil revelam diversas situações em que 
grupos sociais afetados por diferentes projetos econômicos rejeitam o estado de privação e/ou risco a que estão submetidos".

Nesse sentido, há uma ausência de aparato estatal em grande parte dos conflitos existentes em solo brasileiro. Assim, não há como garantir que haja uma efetividade do Poder Público no que tange aos conflitos socioambientais, se a mesma instituição responsável pela aplicação de normas e sanções é também a instituição responsável pelo desenvolvimento desses conflitos. Como é cediço, o conceito de conflito deve ser analisado sob a ótica de quem o define, haja vista que é possível que haja grande variação de acordo com o respectivo observador e definidor.

\subsection{Princípios relacionados}

Os princípios articuladores do Direito Ambiental são grandes vetores e bases que influenciam e podem direcionar a construção normativa do ordenamento jurídico ligado diretamente à questão ambiental. No que tange aos dispositivos jurídicos presentes no contexto legislativo ambiental, os princípios são utilizados como fonte para o desenvolvimento de códigos e leis que determinam limitações ou atribuições de direitos e deveres com o objetivo central de conservar o meio ambiente e controlar os fatores internos e externos que podem vir a modificá-lo.

De acordo com Mirra (1996, p. 341), "os princípios prestam importante auxílio no conhecimento do sistema jurídico, no sentido de uma melhor identificação da coerência e unidade que fazem de um corpo normativo qualquer um verdadeiro sistema lógico e racional".

Apesar de ser um conceito bastante amplo e pautado com frequência no ordenamento jurídico, os princípios variam de acordo com a vertente jurídica e com a forma com que o Direito do caso concreto se apresenta. Acerca do Direito Ambiental, Mirra (1996, p. 343) registra que

[...] tais princípios podem ser localizados e extraídos da Constituição Federal de 1988, da Lei da Política Nacional do Meio Ambiente (Lei Federal 6.938/81), das Constituições Estaduais e, também, ao nosso ver, das Declarações Internacionais de Princípios, adotadas por Organizações Internacionais, em especial as Declarações da ONU de Estocolmo de 1972, sobre o meio Ambiente Humano, e do Rio de Janeiro de 1992, sobre meio Ambiente e Desenvolvimento.

Não obstante, cabe ao jurista e ao legislador analisarem com cautela a função dos princípios fundamentais ao Direito Ambiental no ordenamento jurídico, haja vista que se deve ter em mente que os princípios são norteadores de outras fontes do Direito, mas que devem ser utilizados e interpretados de forma a assegurar a segurança jurídica. Nesse sentido, Milaré (1998, p. 403-404) afırma que

\footnotetext{
o conceito de princípio fundamental não se confunde com a noção de causa nem com a de elemento. Não é causa, porque aquilo que resulta do princípio não é seu efeito. Não é elemento, porque não funciona como parte na formação de um todo. É, antes de um pressuposto que se estabelece como fundamento e ponto de partida. Ora, a ciência jurídica que, em última análise, se ocupa da conduta humana, quer individual quer socialmente, procura tirar suas fundamentações da natureza das coisas mesmas, desenvolvendo-as ao depois, de modo que a organização da sociedade através de um Estado possa atingir mais fácil e fielmente as formas que correspondam ao fim último do mundo natural e da coletividade humana.
}

Deve ser levada em conta também a ausência de exclusividade desses princípios, que é amplamente defendida por doutrinadores, legisladores e estudiosos. Os princípios são fontes amplas do Direito, não cabendo a eles a representação de diversos casos concretos em um entendimento latu sensu. Apesar de haver no ordenamento jurídico brasileiro a presença de princípios jurídicos positivados, não cabe somente ao princípio o julgamento do caso concreto, haja vista que há a necessidade de atuação de normas específicas em conjunto com os princípios para fins de assegurar a segurança jurídica e manter a ordem entre as fontes de Direito que devem ser utilizadas com eficiência. (MILARÉ, 1998, p. 386) 


\section{ROMPIMENTO DE BARRAGEM EM MARIANA/MG}

Dentre inúmeros desastres ocasionados pela ação do homem e que geram consequências de difícil reparação à natureza e às comunidades atingidas, a popularmente conhecida como "tragédia de Mariana/MG" se destacou em níveis nacional e internacional por ter tido danos de grande amplitude, tais como a poluição ambiental, a destruição de comunidades inteiras e a morte de vários civis.

A barragem de Fundão, pertencente à empresa Samarco/SA, se rompeu no dia 05 de novembro de 2015, e, apesar de não se ter uma justificativa exata para seu rompimento, especialistas apontam como a causa principal para o colapso da represa o processo de liquefação. Nesse sentido, a areia presente na parte frontal da barragem retém a água da represa, ao invés de expeli-la. Com isso, a areia se transforma em lama e, consequentemente, deixa de filtrar os resíduos. (LOPES, 2016, p. 5-6)

Além disso, as consequências do rompimento da barragem foram consideradas desastres nunca antes vistos na história da mineração brasileira e mundial. Com dezessete corpos de vítimas encontrados e reconhecidos por seus familiares; com destruição de 1.469 hectares ao longo de $77 \mathrm{~km}$ decursos d'água, incluindo Áreas de Preservação Permanente; com a morte de mamíferos, anfíbios e animais de pequeno porte; e com a dificuldade de moradores de comunidades atingidas pelo desastre de recomeçarem suas vidas, a tragédia da empresa Samarco/SA se tornou emblemática para a história de desastres socioambientais do Brasil. (LOPES, 2016, p. 7-12)

No tocante aos embates jurídicos para resolução e reparação dos danos da tragédia, a Comarca de Mariana, por meio do site do Tribunal de Justiça de Minas Gerais² , divulgou, em novembro de 2017, um balanço de todas as ações envolvendo a Samarco/SA e a tragédia do rompimento da barragem de Fundão. 0 processo $n^{\circ}$ 0400.15.004335-6, de 05 de novembro de 2015, objetiva ressarcir os danos patrimoniais e morais causados aos atingidos que sobreviveram ao rompimento da barragem de Fundão, no Município de Mariana. Já o processo cautelar $n^{\circ}$. 0400.15.003989-1 permite o bloqueio de $\mathrm{R} \$ 300$ milhões da empresa para garantir o ressarcimento integral dos danos causados aos atingidos.

Além disso, o processo $\mathrm{n}^{\circ}$ 0400.16.001476-9, de autoria dos familiares de uma vítima menor de idade que faleceu com o desastre, foi encerrado com um acordo de, aproximadamente, R\$ 620 mil, homologado por sentença em 24 de abril de 2017. Os processos nº 0400.15.004457-8 e 0400.16.000368-9, que dizem respeito ao ressarcimento de danos, encontram-se, até a data da publicação da notícia, em fase de perícia para apuração dos danos.

Nesse sentido, cabem, aos estudiosos e juristas, a busca de meios para qualificar o desastre e seus respectivos danos. No tocante à presente pesquisa, é imprescindível a citação do Princípio do Meio Ambiente Ecologicamente Equilibrado, onde há a ideia central de que o meio ambiente é um direito fundamental. Édis Milaré (1998, p. 387), ao discorrer sobre esse princípio, fala que "reconhecimento do direito a um meio ambiente sadio configura-se, na verdade, como extensão do direito à vida". Assim, como assegurar às vítimas sobreviventes do desastre o equilíbrio ecológico que elas devem ter por direito?

Com isso, surge o Princípio da responsabilização das condutas e atividades lesivas ao meio ambiente, que, de acordo com Álvaro Mirra (1996, p. 355), é

[...] um poluidor, por um mesmo ato de poluição, pode ser responsabilizado, simultaneamente, nas esferas civil, penal e administrativa, com a viabilidade de incidência cumulativa desses sistemas de responsabilidade em relação a um mesmo fato danoso.

2 Para informações adicionais, acesse: http://www.tjmg.jus.br/portal-tjmg/noticias/comarca-de-mariana-divulga-balanco-de-acoes-envolvendo-samarco.htm\#. Acesso em: 19 abr. 2018. 
Assim, cabe à empresa Samarco/SA, por meio das ações públicas já supracitadas, ressarcir as vítimas sobreviventes e os familiares dos de cujus, além de buscar soluções possíveis para a reparação dos danos socioambientais causados pelo rompimento da barragem.

Ainda assim, o Princípio da Participação Popular na Proteção do Meio Ambiente, definido por Mirra (1996, p. 348-349) como "a participação nos processos de criação do Direito Ambiental, a participação na formulação e na execução de políticas ambientais e a participação por intermédio do Poder Judiciário", se torna presente no caso concreto, ao se ter Ações Civis Públicas de órgãos públicos, ONGs e da comunidade em geral em prol da reparação do meio ambiente e do ressarcimento dos danos morais e patrimoniais.

Por fim, o Princípio da Intervenção Estatal Obrigatória na Defesa do Meio Ambiente, descrito no item 17 da Declaração de Estocolmo de 1972 e no art. 227, caput, da Constituição Federal de 1988, expressa o dever de o Poder Público atuar na defesa do meio ambiente, demandado ao próprio Estado a adoção de políticas públicas e programas de ação que possibilitem o cumprimento desse princípio. (MIRRA, 1996, p. 347)

No caso concreto, houve a necessidade de uma intervenção estatal direta na resolução do litígio, tendo em vista fatores internos, como a vulnerabilidade social das comunidades afetadas e a alta poluição do território brasileiro, e fatores externos, como o enfoque midiático na busca por informações e possíveis soluções para os diversos problemas e as cobranças exteriores existentes entre a União e as Organizações Internacionais. (RIOS, 2016, p. 06)

\section{CONFLITO TERRITORIAL ENTRE FACENE E COMUNIDADES DE AREIA BRANCA/RN}

Junto à Prefeitura Municipal de Areia Branca/RN, a Faculdade de Enfermagem e de Medicina Nova Esperança (FACENE) adquiriu terras das comunidades de Morro Pintado e de São Cristóvão, por meio de um leilão da empresa já extinta Agrícola Dunas. De acordo com membros da Associação de Desenvolvimento Comunitário de São Cristóvão - ADESC, a FACENE, ao adquirir o imóvel, pretende construir condomínios que irão atingir dunas, cajueiros e até mesmo falésias ${ }^{3}$.

Não obstante, relatos de moradores que resistem à expulsão de membros das áreas supostamente leiloadas alcançam a seara jurídica. 0 site da Assembleia Legislativa do Rio Grande do Norte emitiu, em 2016, uma nota sobre a audiência que discutia os conflitos sobre terras no município de Areia Branca/ RN. Enquanto o advogado representante da FACENE alegava que a instituição de ensino tem como objetivo transformar as áreas leiloadas em uma área urbana com sustentabilidade, os moradores das duas comunidades acusaram a empresa de não ter permitido diálogo entre as partes ${ }^{4}$.

Além da falta de diálogo, os moradores da comunidade, que utilizam das terras para manter a própria subsistência, manter a subsistência de seus familiares e permitir a economia solidária entre as comunidades, acusam funcionários da FACENE de derrubar caiçaras, furtar redes dos pescadores, destruir barracos de pescadores próximos à praia, cercar determinados locais e impedir a circulação dos moradores.

3 Dados da entrevista entre um representante da ADESC e jornalistas locais colhidos no site http://marsemfim.com.br/especulacao-em-areia-branca-provoca-reacao. Acesso em: 19 abr. 2018.

4 Informações retiradas do site da Assembleia Legislativa do Rio Grande do Norte, disponível em http://www.al.rn.gov.br/portal/ noticias/6387/audincia-discute-conflitos-sobre-terras-no-municpio-de-areia-branca. Acesso em: 19 abr. 2018. 
Na seara jurídica, está em discussão a extensão territorial leiloada para a FACENE. Enquanto as matrículas dos terrenos transferidas para a empresa somavam 6.876 hectares, as mesmas matrículas encerradas pela já extinta empresa Agrícola Dunas dispuseram de uma área medida de somente 5.271 hectares.

Não obstante, os moradores das comunidades ainda sofrem com a ausência de visibilidade devida para o caso concreto, haja vista o desrespeito com a história das comunidades, suas moradias e suas atividades agrícolas e pesqueiras que favorecem a economia local e regional. Assistidos somente pelo site oficial da Assembleia Legislativa do Rio Grande do Norte e por alguns poucos outros sites de notícias locais, o litígio passa a ser objeto de censura dos grandes empresários e políticos que, preocupados com os direitos personalíssimos de seus empreendimentos, preferem não comentar sobre o caso.

Conflitos socioambientais, além das definições supracitadas, podem ser definidos como "confronto de interesses distintos entre atores sociais, tendo como objeto de disputa os recursos naturais, no que se refere à multiplicidade de percepções do seu uso e gestão, sempre ocasionando impactos diretos ou indiretos nas esferas ambiental, social e/ou econômica"5 . Assim, o caso concreto pode ser caracterizado como um conflito socioambiental que tem como litigantes comunidades socioeconomicamente vulneráveis e comumente marginalizadas pelo Estado.

O primeiro princípio que pode ser diretamente ligado ao caso concreto é o Princípio do Respeito à Identidade, Cultura e Interesses das Comunidades Tradicionais e Grupos Formadores da Sociedade, que representa o meio ambiente não apenas como meio natural, mas também como meio artificial (ou urbano) e, ainda, o meio cultural. Além disso, no que tange ao patrimônio cultural, além da preservação ambiental, deve ser preservada também a memória social e antropológica do homem. (MIRRA, 1996, p. 357)

Nesse sentido, os moradores dessas comunidades, como resultado da expansão socioterritorial do nordeste brasileiro, devem ter sua identidade preservada e seu espaço de moradia e de realização de atividades respeitado, haja vista a estabilização desses pescadores e trabalhadores rurais centenários nas terras do município de Areia Branca/RN.

Milaré (1998) cita o Princípio da Função Socioambiental da Propriedade, no qual é possível relacionar com o fato concreto de que as comunidades estão utilizando da propriedade como meio de conceder a si mesmos o bem-estar social disposto no Art. $5^{\circ}$, XXII e XXIII da CF/88. Assim, apesar do conflito estar sustentado pelos interesses de ambas as partes no uso dessas terras, é necessária uma análise histórica para que haja a fragmentação das necessidades econômicas e prevaleça a necessidade social e cultural das comunidades.

Além disso, há o Princípio da Natureza Pública da Proteção Ambiental, no qual o poder público deve se posicionar sobre conflitos socioambientais que põem em risco o caráter jurídico do meio ambiente ecologicamente equilibrado como sendo um bem de uso comum do povo ${ }^{6}$. No caso concreto, o direito ao uso desse território, por meio de justificativas que versam entre a história da emancipação dessas comunidades e a situação de vulnerabilidade (e, em alguns casos, miserabilidade) dos membros dessas comunidades, fica cerceado por intenções meramente econômicas da Prefeitura de Areia Branca e da FACENE.

5 Definição adotada pelo Grupo de Pesquisa sobre Conflitos Socioambientais na Zona Costeira do Rio Grande do Norte, da Universidade Federal do Rio Grande do Norte (UFRN)

6 DERANI apud MILARÉ. 1998, p. 388. 
Cabe ao poder público, portanto, o dever de se mobilizar para assegurar o equilíbrio entre a lide e o meio ambiente, não permitindo ações danosas ao meio ambiente (como a destruição de plantações dos moradores por meio dos funcionários da instituição), buscando soluções para o conflito que assegurem que as comunidades não sejam mais uma vez marginalizadas pelo Estado.

\section{SUPERPOPULAÇÃO INTEMPESTIVA NO ESTADO DE RORAIMA EM 2018}

Como consequência de uma crise política na Venezuela, diversos migrantes e refugiados ultrapassaram a fronteira entre o seu país e o Brasil, tendo como entrada o estado de Roraima, na região Norte do país. Com isso, o estado rapidamente teve diversas instituições públicas superlotadas pelos venezuelanos que buscavam auxílio para manter a subsistência no país que os acolhia.

Além dos problemas sociais de readaptação e recepção dos refugiados em terras brasileiras, a Organização das Nações Unidas no Brasil apontou, em uma matéria feita no site oficial ${ }^{7}$ da ONU Brasil, alguns impactos ambientais como consequência dessa superpopulação na capital do estado, Boa Vista, e em outras cidades.

De acordo com dados colhidos pelo oficial de assuntos humanitários da ONU Meio Ambiente, Daniel Stothart, os mais de 40 mil venezuelanos vivendo na capital de Roraima têm dificuldade em esvaziar as fossas sépticas dos centros de acolhimento, que também estão acolhendo mais pessoas do que o esperado e não oferecem um sistema de saneamento básico que atenda as demandas da população.

Além disso, a demasiada produção de lixo hospitalar derivado de centenas de atendimentos diários realizados por órgãos de saúde para manter os refugiados saudáveis e vacinados também surge como um problema ambiental. Esses resíduos, que carecem de um tratamento específico, se acumulam nos próprios órgãos hospitalares e passam a apresentar riscos à saúde dos refugiados e dos residentes do estado.

No que concerne à subsistência dos venezuelanos, bens ambientais, como água e lenhas para realizar o cozimento de alimentos, são motivos de batalha diária e refletem em danos socioambientais que atingem os moradores das cidades. A escassez de água, o esgotamento do lençol freático na fronteira entre os dois países e o desmatamento em prol da construção de moradias para uso de lenhas acometem o estado de Roraima em um contexto que atinge os refugiados, o estado de Roraima e a União.

Não obstante, a dificuldade dos venezuelanos de se estabilizarem nas cidades de Roraima se caracteriza também pela falta de oportunidade de ingresso no mercado de trabalho que, além de ser escassa para os brasileiros naturalizados, se torna de impossível acesso aos refugiados. Assim, os venezuelanos, agora também, como pessoas em situação de rua, recorrem aos pedidos e malabares em sinais de trânsito, à prostituição e ao furto e roubo. Com isso, os conflitos que já careciam de políticas ambientais e urbanísticas mais eficazes passam a carecer também de políticas sociais de inclusão desses novos grupos em território nacional.

Dentre os diversos princípios definidos por Milaré (1998, p. 392), o cenário supracitado traz à discussão o Princípio do Poluidor-Pagador (polluter pays principle), que se ampara na ideia de que os "custos sociais externos que acompanham o processo produtivo devem ser internalizados, vale dizer, que os agentes econômicos devem levá-los em conta ao elaborar os custos de produção e, consequen-

7 Dados explanados no presente trabalho retirados da matéria do link https://nacoesunidas.org/falta-de-servicos-para-atender-venezuelanos-em-roraima-tem-impacto-ambiental/. Acesso em: 21 abr 2018. 
temente, assumi-los". Sendo assim, caberia aos refugiados, ao cogitarem a migração para o território brasileiro, o dever de planejamento de custos para possíveis danos ambientais?

O Princípio do Poluidor-Pagador deixa bem claro que a poluição deve ser consequência de uma finalidade econômica de um determinado agente. Sendo assim, o referido princípio, apesar de ter base teórica para conceituar no caso concreto o agente poluidor e as consequências da poluição, deve se ancorar também no contexto ao qual os agentes envolvidos (sejam eles pessoas naturais, pessoas jurídicas de direito público, pessoas jurídicas de direito privado) estão inseridos, em que fatores externos como a extraterritorialidade do conflito, por exemplo, podem dificultar a aplicação da fonte do direito.

Outro princípio conceituado por Milaré (1998) é o Princípio da Prevenção, que, no caso concreto, deve ser visto como Princípio da Precaução. Ambos os princípios representam a responsabilidade do agente de prever possíveis danos ambientais e, com isso, assumir atitudes e/ou definir políticas que diminuam a probabilidade de uma determinada atividade gerar um impacto no meio ambiente. O Princípio da Precaução, por ser medida antecipatória para casos concretos, surge no atual cenário como instrumento para que o Estado, entendendo a crise de refugiados em Roraima, ofereça meios de cessar os impactos socioambientais presentes no território.

Assim, o Estado não deve se valer de medidas extremistas, como o fechamento da fronteira entre Brasil e Venezuela, haja vista só seria possível cessar a entrada de mais refugiados, mas não resolveria os problemas já presentes no território brasileiro. Como preventor, o Estado deve oferecer políticas de saneamento básico e de destinação de resíduos hospitalares mais eficazes na região, além de dispor de bens públicos dominicais que, ao não terem uma destinação, podem servir como abrigo para os refugiados. Além disso, o Estado pode atuar junto de órgãos internacionais para promover ações de acolhimento e de ressocialização dos refugiados em institutos brasileiros, evitando outros conflitos sociais que possam surgir entre os estrangeiros e os domiciliados no país.

Por fim, Mirra (1996, p. 358) conceitua o Princípio da cooperação internacional em matéria ambiental como

\footnotetext{
a) o dever de informação de um Estado aos outros Estados, nas situações críticas capazes de causar prejuízos transfronteiriços;
}

b) o dever de informação e consulta prévia dos Estados a respeito de projetos que possam trazer efeitos prejudiciais aos países vizinhos;

c) o dever de assistência e auxílio entre os países nas hipóteses de degradações ambientais importantes e catástrofes ecológicas;

d) o dever de impedir a transferência para outros Estados de atividade ou substâncias que causem degradação ambiental grave ou que sejam prejudiciais à saúde humana - é o problema da "exportação de poluição".

Assim, esse princípio, previsto na Declaração do Rio sobre Meio Ambiente e Desenvolvimento, de 1992, e na Declaração de Estocolmo sobre o Meio Ambiente Humano, de 1972, garante a cooperação entre Estados em prol do meio ambiente extraterritorial. No caso concreto, a instabilidade política vivenciada pela Venezuela se apresenta como um obstáculo na efetivação desse princípio, em que há somente a atuação do Estado brasileiro como interventor nos problemas socioambientais que envolvem ambos os países. 


\section{CONCLUSÃO}

Os conflitos socioambientais existentes em território brasileiro ainda carecem de uma atuação jurídica mais eficiente e em consonância com as fontes formais e materiais disponíveis pelo ordenamento jurídico brasileiro. Além de leis negligenciadas, diversas doutrinas são ignoradas por grandes empresas, legisladores e profissionais em geral, quando há a busca pelo desenvolvimento econômico público e/ou privado.

Os princípios norteadores de Direito Ambiental, presentes em códigos, doutrinas e documentos internacionais que já integram o ordenamento jurídico brasileiro, devem ser relacionados com todos os litígios específicos que estão em curso no judiciário ou que ainda não alcançaram a seara judicial. Assim, a probabilidade de extensas discussões e de processos delongados que causam superlotação processual podem ser evitados por meio dessa efetivação principiológica.

O poder público, dotado de atribuições que o tornam mais robusto e fortalecido para a resolução de conflitos de caráter público e privado, deve preparar os agentes públicos para a prevenção de conflitos ou, se for o caso, a reparação das consequências causadas por eles. Ora, é de todo necessário a quantidade de princípios norteadores do Direito Ambiental que se utilizam do Estado como ferramenta de efetivação de direitos, haja vista a responsabilidade e os instrumentos disponíveis que o poder público tem para evitar ou deliberar sobre conflitos socioambientais.

Apesar disso, o Estado deve se valer dos princípios de forma a alcançar o equilíbrio socioambiental entre todos os indivíduos. 0 poder público, ao tratar de matéria ambiental, não deve utilizar do judiciário somente para a manutenção do status quo do Estado como monopólio legítimo da força coercitiva, sem utilizar como base os princípios articulados nas diversas conferências internacionais, os interesses das partes e a justiça do caso concreto. Cabe ao Estado e à sociedade a responsabilidade pelo entendimento, disseminação e aplicação dos princípios norteadores do Direito Ambiental para garantir o meio ambiente ecologicamente equilibrado entre todas as comunidades. 


\section{REFERÊNCIAS}

ALVES, Stevam Gabriel; SANTOS, Solange Laurentino dos. Injustiças e Conflitos Socioambientais: o que são e como surgem?. Revista Gestão \& Sustentabilidade Ambiental, [s.I.], v. 6, n. 2, p.216-226, 1 ago. 2017. Universidade do Sul de Santa Catarina - UNISUL.

ANTUNES, Paulo de Bessa. Direito Ambiental. 7. ed. Rio de Janeiro: Editora Lúmen Juris, 2005.

BRASIL. Constituição Federal. Promulgada em 05.10.1988.

Política Nacional do Meio Ambiente. Lei nº 6.938, de 31.08.1981.

BRITO, Daguinete Maria Chaves et al. Conflitos socioambientais no século XXI. Pracs: Revista de Humanidades do Curso de Ciências Sociais da Unifap, Macapá, n. 4, p.51-58, dez. 2011.

CARVALHO, Izabel Cristina de Moura \& SCOTTO, Gabriela. IV Fórum de Educação Ambiental. I Encontro da Rede Brasileira de Educação Ambiental. Projeto Roda-Viva (org.). Instituto Ecoar para a Cidadania. Rio de Janeiro: INESC, 1997. p. 129-132.

GRANZIERA, Maria Luiza Machado. Direito Ambiental. 3. ed. São Paulo: Atlas, 2014.

GUERRA, Sidney. GUERRA, Sérgio. Curso de Direito Ambiental. 2. ed. São Paulo: Editora Atlas, 2014.

LOPES, Luciano M. N. 0 rompimento da barragem de Mariana e seus impactos socioambientais. Sinapse Múltipla, Belo Horizonte, v. 5, n. 1, p.1-14, jun. 2016. Disponível em: <http://periodicos.pucminas.br/ index.php/sinapsemultipla/article/download/11377/9677 >. Acesso em: 17 abr. 2018.

MALUF, Adriana Caldas do Rego Freitas Dabus. Limitações urbanas ao direito de propriedade. São Paulo: Atlas, 2010.

MILARÉ, Edis. Direito do ambiente: doutrina, pratica, jurisprudência, glossário. São Paulo: Editora Revista dos Tribunais, 2001.

Princípios Fundamentais do Direito do Ambiente. Revista dos Tribunais, [S.I.], v. 756, n. 53, p.385-404, out. 1998.

MIRRA, Álvaro Luiz Valery. Princípios Fundamentais do Direito Ambiental. Revista de Direito Ambiental, [S.I.], v. 2, n. 50, p.339-360, jun. 1996.

PERON, Geraldo Magela. 0 direito fundamental da propriedade privada. Jurisway, [S.I.], nov. 2012. Revista eletrônica. Disponível em: <https://www.jurisway.org.br/v2/dhall.asp?id_dh=9339>. Acesso em: 30 mar. 2018.

RED MESOAMERICANA DE MANEJO DE CONFLICTOS SOCIOAMBIENTALES. Conflictos socio ambientales en América Latina: una visión desde la Red Mesoamericana de Manejo de Conflictos Socio Ambientales. Costa Rica: Universidad para la Paz, 1999.

RIOS, Ricardo Matos de Araújo. A repercussão internacional do acidente de Mariana no The New York Times e na CNN. In: $3^{\circ}$ SEMINÁRIO DE RELAÇÕES INTERNACIONAIS: GRADUAÇÃO E PÓS-GRADUAÇÃO, 3., 2016, Florianópolis: Pontifícia Universidade Católica de Minas Gerais, 2016. p. 1 - 14. 
ROOS, Alana. Agricultura: dos povos nômades aos complexos agroindustriais. Rev. Elet. em Gestão, Educação e Tecnologia Ambiental, Santa Maria, v. 7, n. 7, p.1423-1429, ago. 2012.

SILVA, José Afonso da. Direito Ambiental Constitucional. 4. ed. São Paulo: Malheiros Editores, 2002. Direito Urbanístico Brasileiro. 6. ed. São Paulo: Malheiros Editores, 2010.

SIRVINSKAS, Luís Paulo. Manual de Direito Ambiental. 13. ed. São Paulo: Saraiva, 2014. 